\title{
Supplementary Educational Models in Canadian Neurosurgery Residency Programs
}

\author{
Won Hyung A. Ryu, Sonny Chan, Garnette R. Sutherland
}

\begin{abstract}
Background: The proposed implementation of work hour restrictions has presented a significant challenge of maintaining the quality of resident education and ensuring adequate hands-on experience that is essential for novice surgeons. To maintain the level of resident surgical competency, revision of the apprentice model of surgical education to include supplementary educational methods, such as laboratory and virtual reality (VR) simulations, have become frequent topics of discussion. We aimed to better understand the role of supplementary educational methods in Canadian neurosurgery residency training. Methods: An online survey was sent to program directors of all 14 Canadian neurosurgical residency programs and active resident members of the Canadian Neurosurgical Society $(\mathrm{N}=85)$. We asked 16 questions focusing on topics of surgeon perception, current implementation and barriers to supplementary educational models. Results: Of the 99 surveys sent, 8 out of 14 (57\%) program directors and 37 out of 85 (44\%) residents completed the survey. Of the 14 neurosurgery residency programs across Canada, 7 reported utilizing laboratory-based teaching within their educational plan, while only 3 programs reported using VR simulation as a supplementary teaching method. The biggest barriers to implementing supplementary educational methods were resident availability, lack of resources, and cost. Conclusions: Work-hour restrictions threaten to compromise the traditional apprentice model of surgical training. The potential value of supplementary educational methods for surgical education is evident, as reported by both program directors and residents across Canada. However, availability and utilization of laboratory and VR simulations are limited by numerous factors such as time constrains and lack of resources.
\end{abstract}

RÉSUMÉ: Modèles pédagogiques supplémentaires dans les programmes canadiens de résidence en neurochirurgie. Contexte $:$ La mise en place de restrictions des heures de travail qui a été proposée présentait un défi important pour le maintien de la qualité de la formation des résidents et donc pour l'acquisition d'une expérience pratique adéquate indispensable aux nouveaux chirurgiens. Afin de maintenir le niveau de compétence chirurgicale des résidents, une refonte du modèle d'apprentissage de la formation chirurgicale pour y inclure des méthodes de formation supplémentaires telles des simulations en laboratoire et de réalité virtuelle (RV) sont des sujets de discussion de plus en plus fréquents. Notre but était de mieux comprendre le rôle des méthodes d'apprentissage complémentaires dans la formation des résidents canadiens en neurochirurgie. Méthodologie : Nous avons effectué une enquête en ligne auprès des directeurs de programme des 14 programmes de résidence en neurochirurgie du Canada et des résidents, membres actifs de la Société canadienne de neurochirurgie $(\mathrm{N}=85)$. Nous avons posé 16 questions ciblant les sujets suivants concernant les modèles pédagogiques complémentaires : la perception des chirurgiens, la mise en place actuelle et les obstacles à la mise en place de ces modèles pédagogiques. Résultats : Quatre-vingt-dix-neuf questionnaires ont été envoyés et 8 des 14 directeurs de programme (57\%) l'ont complété de même que 37 des 85 résidents (44\%). Sept des 14 programmes de résidence en neurochirurgie au Canada utilisent l'enseignement en laboratoire dans le cadre de leur curriculum alors que seulement 3 utilisent la RV comme méthode pédagogique d'appoint. Les principaux obstacles à la mise en place de méthodes pédagogiques d'appoint étaient la disponibilité des résidents, le manque de ressources et leur coût. Conclusions : La restriction des heures de travail menace de compromettre le modèle d'apprentissage traditionnel de formation chirurgicale. La valeur potentielle des méthodes pédagogiques d'appoint en chirurgie est évidente, comme le signalent tant les directeurs de programme que les résidents à travers le Canada. Cependant, la disponibilité et l'utilisation de simulations en laboratoire et de RV sont limitées par plusieurs facteurs tels les contraintes de temps et le manque de ressources.

Keywords: Education, neurosurgery, simulation

doi:10.1017/cjn.2016.315

Can J Neurol Sci. 2017; 44: 177-183

\section{INTRODUCTION}

A comprehensive knowledge of anatomy and surgical technique are fundamental to becoming a competent surgeon.
Neurosurgical residents across Canada commit 6 or more years towards achieving this goal. While the end goal of all neurosurgery residency training is the same across Canada, reflecting

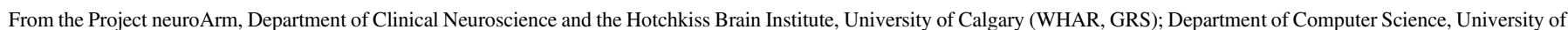
Calgary (SC), Alberta, Canada.

Received January 11, 2016. Final Revisions Submitted March 28, 2016. Date of Acceptance April 20, 2016

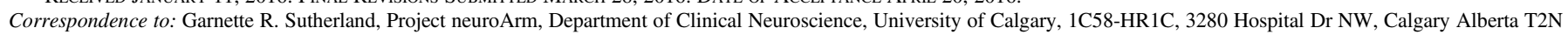
4Z6. Email: garnette@ucalgary.ca 
the Royal College of Physicians and Surgeons requirements, currently the 14 neurosurgery programs operate with individual educational plans that are unique to each institution. Unfortunately, this can result in a wide variability in exposure to anatomical teaching and surgical technique education.

Adding to the challenge of resident education is the growing concern over work hour restriction and its potential negative impact in accruing hands-on experience that is essential for novice surgeons. ${ }^{1}$ Indeed, essential building blocks towards surgical competency include clinical judgment and technical skills that cannot be learned simply based on didactic teaching. While the Canadian residency programs have not been formally mandated to an absolute work hour restriction, the effect of work hour restriction is more evident in the USA. This includes decrease in operative experience, significant lack of operative confidence and perceived disruption of continuity of care. ${ }^{1-4}$ To maintain the level of resident surgical competency, revision of the apprentice model of surgical education to include supplementary educational methods, such as surgical "Rookie Camp" for junior residents, laboratory and virtual reality simulations, have become frequent topics of discussion in surgical and educational literature. $^{5-10}$

As Canadian residency training programs enact more stringent work hour restrictions it is important to assess the current effectiveness of resident training in surgery. To our knowledge there are no published studies examining the anatomy and surgical technique training that Canadian neurosurgery residents receive. The purpose of this study was to conduct a nation-wide survey of both residency program directors and resident physicians on the utility, availability, and barriers to implementation of laboratory and simulation-based education.

\section{MeTHODS}

\section{Study Setting and Design}

We conducted a prospective cohort study. An online survey with a cover letter stating the study objective was sent to residency program directors from all 14 Canadian neurosurgery programs. The contact information was obtained through the Royal College of Physician and Surgeon of Canada. ${ }^{11}$ All 85 active resident members of the Canadian Neurosurgical Society (CNSS) were also invited to participate in the online survey. Based on the 2014-2015 national census, there were 114 Canadian trained neurosurgery residents. ${ }^{12}$ The University of Calgary Research Ethics Board has approved this research study. Reminder emails were sent at 4 and 8 weeks after the initial invitation.

\section{Primary Measurement}

The online survey included 16 questions regarding the teaching of anatomy and surgical techniques, exposure to virtual reality surgical simulation, availability of laboratory dissection (cadaveric and animal), and resident evaluations (Table 1). The questions were both developed by the authors and derived from previously published studies. ${ }^{13-16} \mathrm{We}$ further modified the survey design to collect qualitative data through incorporating multiple comment sections where responders could provide additional comments. The responses were collected anonymously and stratified by residency levels (PGY 1-6) and by position (program director vs. resident).

\section{Statistical Analysis}

Descriptive statistics were used to examine the respondents' answers to the survey questions. The responses were grouped based on the respondent's position (program director vs. resident) and years in training (for residents). Statistical analyses were performed using Microsoft Excel.

\section{Results}

Of the 99 surveys sent, 8 of $14(57 \%)$ program directors and 37 of $85(44 \%)$ residents completed the survey within 3 months. Of the residents who responded to the survey, there was a similar distribution of residency levels (Table 2).

\section{Availability and Barriers of Surgical Education}

Of the 14 neurosurgery residency programs across Canada, 7 reported that they utilize laboratory dissection in their training. In contrast only 3 programs reported using virtual reality simulation as a supplementary teaching method. Of the neurosurgery programs currently utilizing laboratory and/or virtual reality simulation sessions, most responders noted that their program formally schedules 1-3 sessions per year (Table 2). Only 1 responder noted that more than 13 sessions of such supplementary methods were scheduled per year. $78 \%$ of respondents reported that all postgraduate level residents (PGY 1 to 6) participated in these sessions. Only 1 program director that completed the survey noted that the residents are formally graded in the laboratory dissection or VR simulation.

Regarding the current barriers to establishing or maintaining laboratory-based teaching, the most frequent response was resident time constraints followed by lack of equipment/resources (Figure 1). The common barriers to implementing VR simulation in residency education included resident time constraints, cost of VR simulation, and lack of equipment/software support (Figure 2). For both laboratory-based and VR simulation, program directors identified lack of resources as the biggest barrier $(86 \%)$, while residents highlighted lack of free time as their biggest barrier $(77 \%)$. One responder further elaborated that supplemental education methods are only sporadically used in the specific program due to concerns over the potential for learning "bad habits" from current VR simulator systems. Furthermore, 5 responders highlighted the lack of validated modules in VR simulations and the lack of evidence of their educational benefit.

\section{Content of Supplementary Surgical Education}

When designing supplementary surgical education curriculum, surgical technique was covered more frequently than anatomy and use of surgical tools or devices (Figure 3). One responder noted the use of laboratory education to practice microscopic surgery. Regarding the use of specific VR simulators, the endoscopic simulator was most commonly utilized, followed by the ventriculostomy simulator (Figure 4).

\section{Utility of Virtual Reality Simulation}

On the perception of virtual reality simulations, $81 \%$ of responders agreed that in the era of work hour restriction and competency-based training, VR technology could be a beneficial supplement to conventional "hands on" training. Furthermore, $64 \%$ of the program directors and residents noted that VR 


\section{Table 1: Online survey sent to neurosurgery program directors and residents}

\begin{tabular}{|c|c|}
\hline What is your position? & $\begin{array}{l}\text { Program director } \\
\text { Resident }\end{array}$ \\
\hline \multirow[t]{6}{*}{ What year of residency are you in? } & 1 \\
\hline & 2 \\
\hline & 3 \\
\hline & 4 \\
\hline & 5 \\
\hline & 6 \\
\hline \multirow{2}{*}{$\begin{array}{l}\text { 1) Do you currently incorporate laboratory (cadaveric or animal) dissection in the } \\
\text { neurosurgery residency program? }\end{array}$} & Yes \\
\hline & No \\
\hline \multirow{2}{*}{$\begin{array}{l}\text { 2) Do you currently incorporate virtual reality (VR) simulation in the neurosurgery } \\
\text { residency program? }\end{array}$} & Yes \\
\hline & No \\
\hline \multirow{5}{*}{$\begin{array}{l}\text { 3) What barriers exist to establishing/maintaining a lab dissection training program at your } \\
\text { institution? (check all that apply) }\end{array}$} & Insufficient space \\
\hline & Resident time constraints \\
\hline & Limited faculty participation \\
\hline & Lacking equipment/resources \\
\hline & Inadequate specimen acquisition/storage Lack of lab coordinator/director \\
\hline \multirow{5}{*}{$\begin{array}{l}\text { 4) What barriers exist to establishing/maintaining a VR simulation training program at your } \\
\text { institution? (check all that apply) }\end{array}$} & Insufficient space \\
\hline & Resident time constraints \\
\hline & Limited faculty participation \\
\hline & Cost of VR simulation equipment/resources/software support \\
\hline & Lack of lab coordinator/director \\
\hline \multirow[t]{5}{*}{ 5) How many sessions per year are formally scheduled? } & 0 \\
\hline & $1-3$ \\
\hline & $4-6$ \\
\hline & $7-12$ \\
\hline & $13-26$ \\
\hline 6) Which post-graduate year residents participate? (check all that apply) & PGY $1,2,3,4,5,6$ \\
\hline \multirow[t]{3}{*}{ 7) What is the primary focus in the laboratory dissection? (check all that apply) } & Anatomy \\
\hline & Surgical technique \\
\hline & Surgical tools/devices \\
\hline \multirow[t]{3}{*}{ 8) What is the primary focus in the VR simulation? (check all that apply) } & Anatomy \\
\hline & Surgical technique \\
\hline & Surgical tools/devices \\
\hline \multirow[t]{8}{*}{ 9) What types of VR simulators are available for residents? (check all that apply) } & None \\
\hline & Cerebrovascular Simulator \\
\hline & Endovascular Simulator \\
\hline & Craniotomy Simulator \\
\hline & Ventriculostomy Simulator \\
\hline & Endoscopic Simulator \\
\hline & Spine Simulator \\
\hline & Other \\
\hline \multirow[t]{2}{*}{ 10) Are residents graded or formally evaluated on the lab dissection? } & Yes \\
\hline & No \\
\hline \multirow{2}{*}{$\begin{array}{l}\text { 11) Are residents graded or formally evaluated on the VR simulation? For the following } \\
\text { statements, indicate whether you agree with the statement. }\end{array}$} & Yes \\
\hline & No \\
\hline \multirow{2}{*}{$\begin{array}{l}\text { 12) Resident use of a VR simulator to practice neurosurgical technique will improve } \\
\text { patient outcomes. }\end{array}$} & Yes \\
\hline & No \\
\hline
\end{tabular}


Table 1: Continued

\begin{tabular}{|c|c|}
\hline \multirow{2}{*}{$\begin{array}{l}\text { 13) In the era of work hour restrictions and competency-based training, VR simulators can be } \\
\text { a beneficial supplement to conventional "hands on" training. }\end{array}$} & Yes \\
\hline & No \\
\hline \multirow{2}{*}{$\begin{array}{l}\text { 14) VR simulation can assist in preparation for complex neurosurgical cases for residents in } \\
\text { training. }\end{array}$} & Yes \\
\hline & No \\
\hline \multirow{2}{*}{$\begin{array}{l}\text { 15) VR simulation can provide an objective measurement of certain surgical skills/ } \\
\text { knowledge. }\end{array}$} & Yes \\
\hline & No \\
\hline \multirow{2}{*}{$\begin{array}{l}\text { 16) VR simulation should become an integral/mandatory (perhaps early in training) aspect of } \\
\text { academic residency program }\end{array}$} & Yes \\
\hline & No \\
\hline
\end{tabular}

Survey modified from Kshettry VR et al., Ganju A et al., and Kirkman et al.

simulation-based teaching should become an integral/mandatory aspect of academic residency programs. Additionally, 72\% responders thought that VR simulators could assist in preparation for or case rehearsal of complex neurosurgical procedures. Approximately half of the responders agreed that residents' use of simulators would improve patient outcome and that simulators could provide objective measurement of certain surgical skills/ knowledge ( $57 \%$ and $55 \%$ respectively). One responder noted that VR technology has the potential to compensate for the limited exposure to certain complex neurosurgical cases such as aneurysm clipping, given the changes in surgical practice pattern. Others raised concerns about the lack of realism and fidelity of current simulation systems.

\section{DISCUSSION}

Our national survey of neurosurgery program directors and residents yielded a $44 \%$ response rate that included 8 of 14 program directors completing the questionnaire. To our knowledge, this is the first national survey to examine surgeons' perception, current utilization and barriers to supplemental educational methods in Canadian surgical residency programs. The survey revealed that the majority of programs incorporated laboratory-

Table 2: Demographic characteristics

\begin{tabular}{l|c}
\hline Position & Total \\
\hline Program directors $(\mathrm{N}=14)$ & 8 \\
\hline Residents $(\mathrm{N}=85)$ & 37 \\
\hline PGY-1 & 5 \\
\hline PGY-2 & 6 \\
\hline PGY-3 & 5 \\
\hline PGY-4 & 7 \\
\hline PGY-5 & 9 \\
\hline PGY-6 & 8 \\
\hline Number of sessions per year (laboratory or/and VR simulation) & 27 \\
\hline 0 & 5 \\
\hline $1-3$ & 3 \\
\hline $4-6$ & 1 \\
\hline $7-12$ & \\
\hline $13+$ & \\
\hline & \\
\hline
\end{tabular}

based training while only $37 \%$ used VR simulation as part of their resident education. The most common barriers to the adoption of these supplementary surgical education methods were resource availability and resident time constraints. It is important to note that while a number of responders raised concerns over the fidelity and validity of current simulation technique, $81 \%$ of the program directors and residents expressed that VR simulation technology could be a beneficial supplement to conventional hands-on training.

The primary goal of every residency-training program is to instill competency in graduating physicians that ensures safe and optimal care of patients. The apprentice model with graduated responsibility stood as the gold standard in the training of novice surgeons for over a century. ${ }^{17,18}$ However, the growing adoption of restricted resident work hours has raised concerns over whether the conventional apprentice model provides sufficient clinical exposure to achieve the necessary medical expertise and technical proficiencies. ${ }^{2,6,19,20}$ This is particularly evident in the surgical specialties, where a growing number of publications report negative effects of work hour restrictions, such as decrease in subspecialty board exam scores, lack of confidence in newly graduated residents, and perceived deterioration of patient care. ${ }^{1-3}$, ${ }^{20}$ For example, a survey of 254 U.S. general surgery programs found that 62 of 121 procedures deemed to be fundamental for surgical competency were performed on average less than twice during the 5 year training program. ${ }^{2}$ Not surprisingly, a recent survey of 653 graduating surgical residents revealed that $25 \%$ of residents lacked confidence in performing eight of 13 common general surgery and trauma procedures. ${ }^{3}$ Similar reports have been published in such surgical specialties as neurosurgery, cardiac surgery and thoracic surgery. ${ }^{1,21}$ To mitigate the potential negative impact of work hour restriction, there is a growing interest in and focus on novel methods of resident education that can address limitations in the apprentice model. ${ }^{10,18}$ These include bench model simulations, cadaveric dissections, live animal models, and VR simulations. ${ }^{10,18,22,23}$ Indeed, the educational benefit of simulation-based surgical training has been highlighted by multiple major neurosurgical societies, including the American Association of Neurological Surgeons and the Congress of Neurological Surgeons, that have worked to develop and incorporate simulation platforms into resident training curriculums. ${ }^{24,25}$ What remains to be determined are surgeons' and users' perceptions of simulation, current implementation of the technologies, and barriers to the implementation of these supplementary educational methods. 


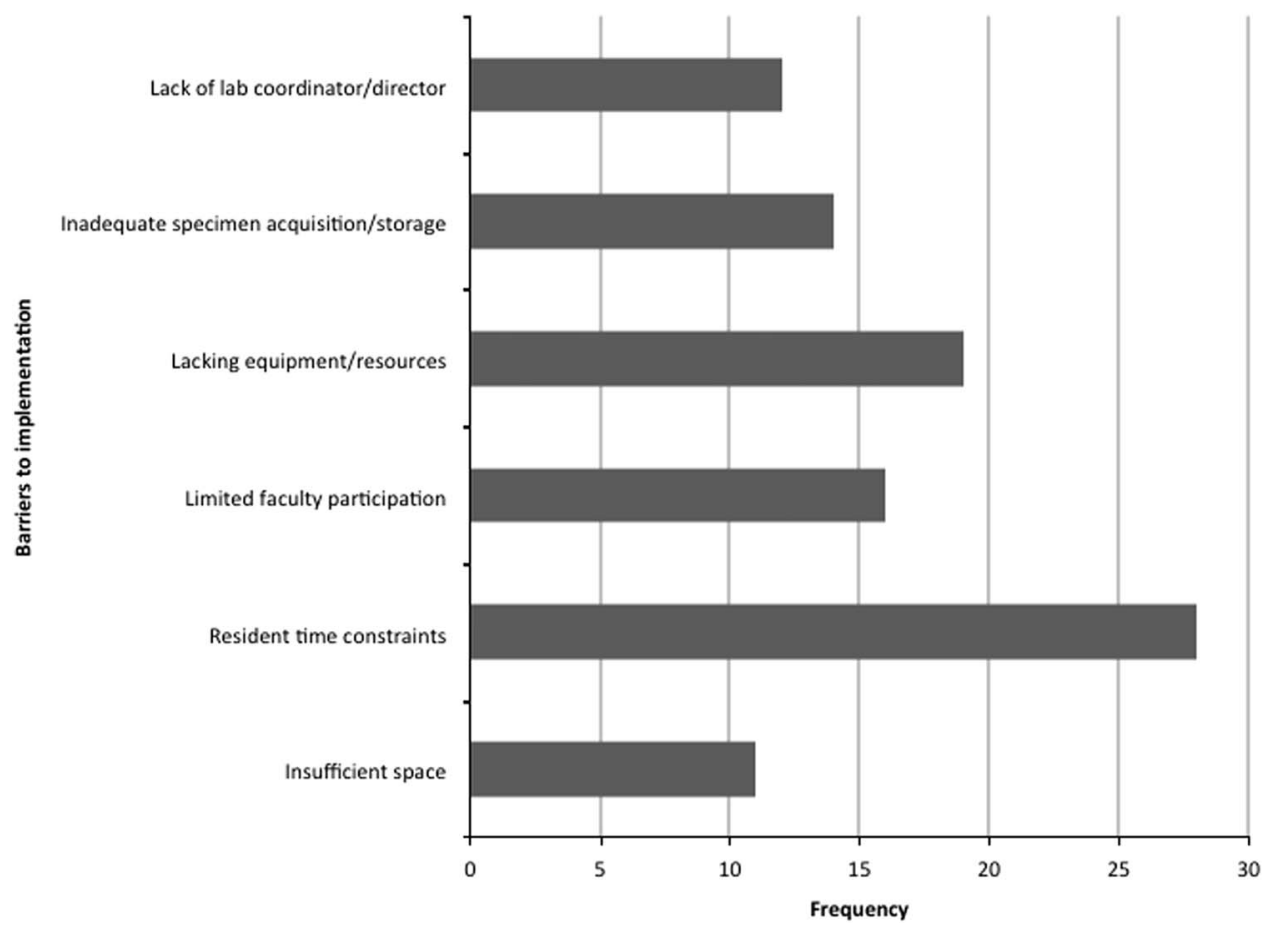

Figure 1: Barriers to laboratory-based supplementary education. Program directors' and resident physicians' responses on the current barriers to implementing and supporting laboratory-based supplementary education model.

While complementing some of the findings from previous studies done in the U.S., our results provide additional insight into the current state of supplementary educational models. Kshettry et al. surveyed 65 U.S. neurosurgery residency program directors and found that the majority of the programs utilize laboratory dissection for resident education. ${ }^{14}$ Furthermore, the most common barrier to laboratory-based supplemental education was resident availability. Kshettry also noted that $69 \%$ of program

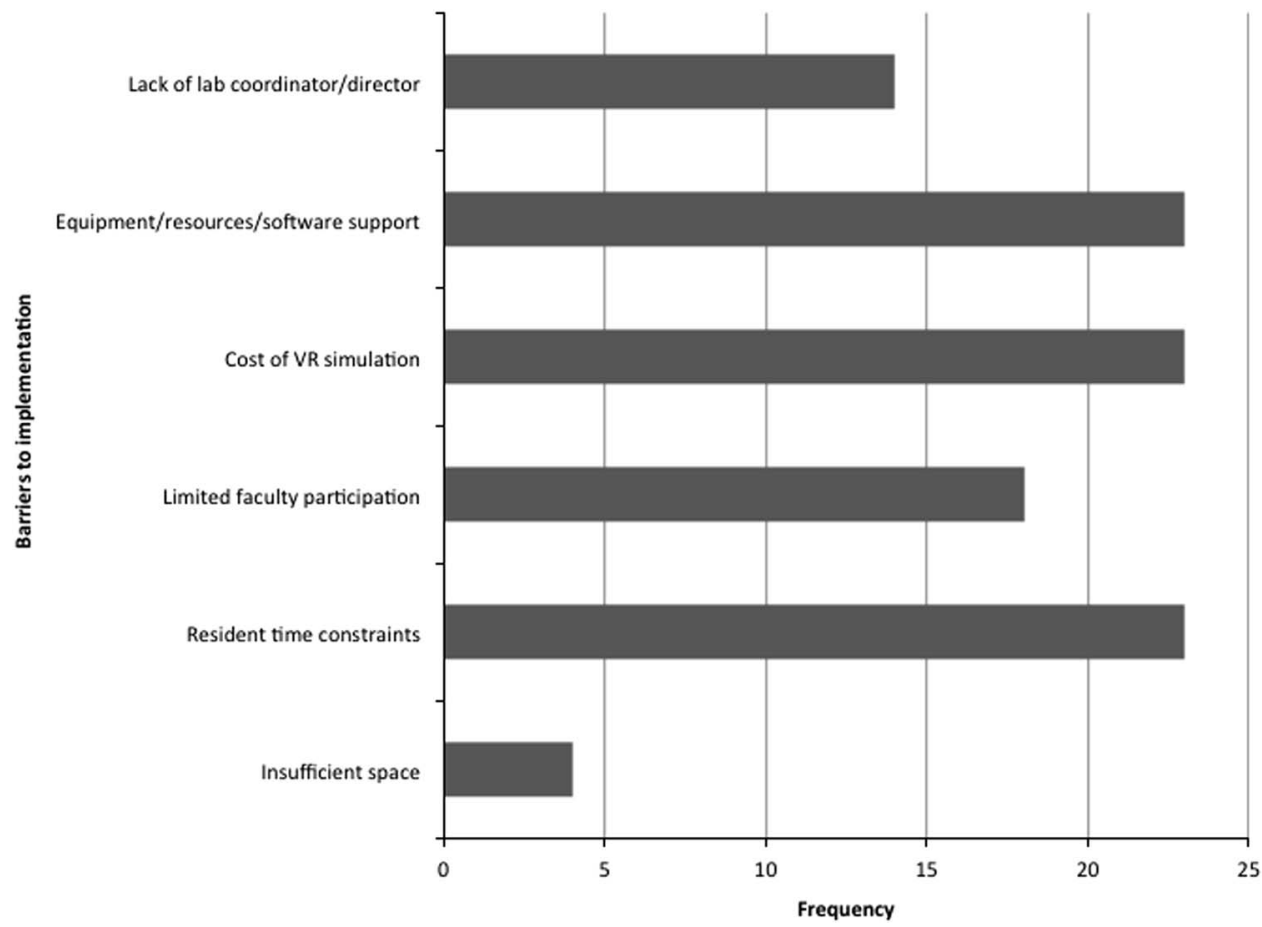

Figure 2: Barriers to VR-based supplementary education. Program directors' and resident physicians' responses on the current barriers to implementing and supporting VR-based supplementary education model. 


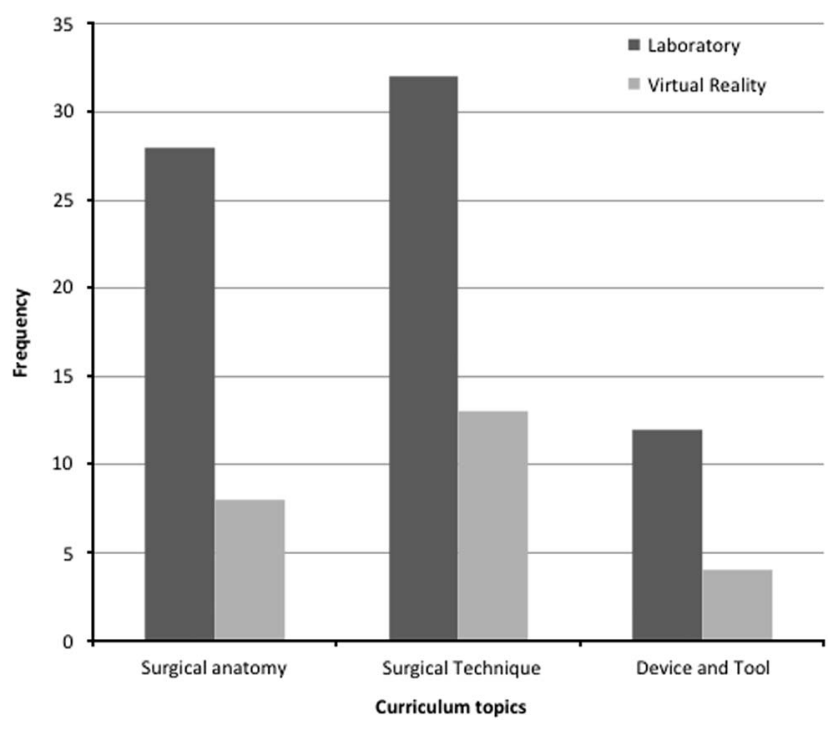

Figure 3: Topics covered in the supplementary education. Distribution of topics covered during the supplementary education sessions.

directors favored laboratory dissection over current simulation models. Unfortunately, it is difficult to delineate the reasons for this finding, as there was no provision of qualitative feedback in this study. Our survey revealed that the preference for laboratory dissection largely stems from concerns over the fidelity and validity of current virtual reality simulators. This preference may also be influenced by the familiarity with cadavaric teaching, commonly utilized by medical schools. However, a number of responders in our survey noted that VR simulation has the potential to compensate for the decreasing clinical exposure to complex surgical cases. As one responder noted, "VR could compensate for the limited number of cases nowadays available: aneurysm clipping is not as commonly done as 20 years ago and the number of cases presenting at individual centres are too few for residents to acquire confidence in clipping." Indeed, the potential utility of VR simulation is substantiated by published

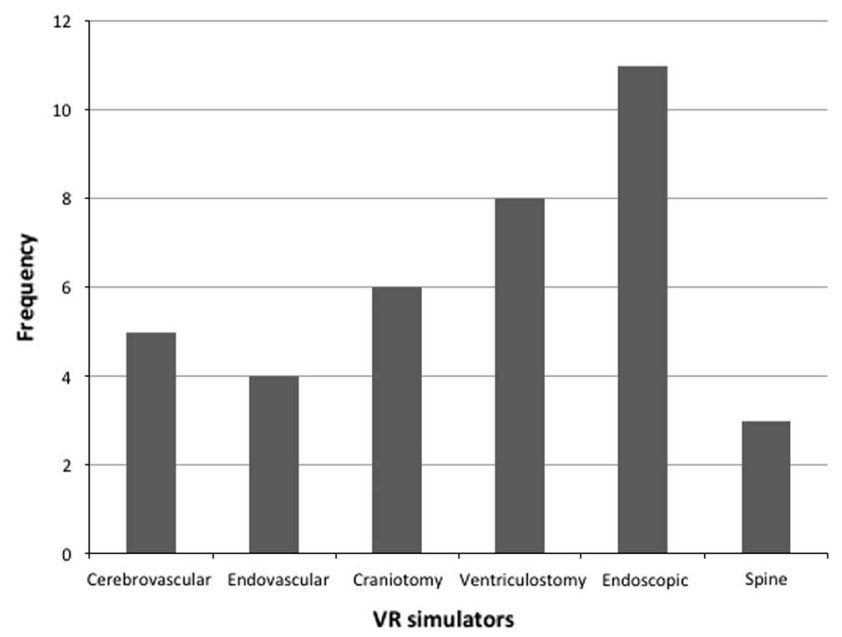

Figure 4: Types of VR simulation. Range of VR simulation models available for resident physicians during the supplementary education sessions. reports that highlight that residents experienced improvement in surgical proficiency after computer-based simulation training. 8,10 Ganju et al. surveyed 53 neurosurgery residency program directors and found that $72 \%$ of respondents believed that simulators would lead to improved patient care and $94 \%$ supported the use of simulators for residents. ${ }^{13}$ This is similar to the findings of our survey where $72 \%$ of responders believed that VR simulation could assist in planning and preparation for complex neurosurgical cases for residents in training and $65 \%$ thought that VR simulation should become an integral aspect of academic residency programs. Furthermore, our survey addressed some of the current barriers to implementing simulators. Specifically, we found that resident availability, cost of simulators, and absence of technical support all hinder the implementation of simulation-based training. But as with any new technology, we would anticipate surgical simulation technology to become more widespread with improved ease of use and decreased cost.

\section{Limitations \& Strength of the study}

This study is limited by a number of factors including incomplete survey response rate, selection bias and lack of survey validation. While we were able to contact the program directors of all 14 Canadian neurosurgery residency programs through the Royal College of Physicians and Surgeons of Canada website, we did not have a complete list of active neurosurgery residents across Canada. Instead, we utilized contact information from the CNSS to recruit resident participation. In the 2014-15 national census, there were 114 Canadian trained neurosurgery residents, compared to the 85 resident members of the CNSS that we contacted for this study. Furthermore, given that survey forms were completed anonymously, it is not possible to determine the distribution of responses based on institution. Thus there is possible selection bias, as programs with a particular interest in laboratory and/or computer-based VR simulation may have been more likely to complete the survey. Lastly, while this survey has been modified based on previously published surgical education surveys found in literature, it has not been validated. We nonetheless believe that our survey has provided new insight into perceptions, current implementation, and barriers to the adoption of these supplementary educational models by engaging multiple program directors and residents across Canada.

\section{Conclusions and Implications for Future Research}

Work hour restrictions have the potential to compromise the traditional apprentice model of surgical training. As is evident from the results of our survey, supplementary methods can potentially benefit surgical education. However, the availability of both laboratory training and computer-based VR simulation training are limited by time constrains and lack of resources. Furthermore, there are concerns over the fidelity and validity of current simulation systems. Additional research into developing and implementing novel supplementary educational methods is required in order to maintain the quality of residency training across Canada. We anticipate that, as technology advances, simulation will be important not only as an educational tool, but also a case rehearsal platform. Furthermore, surgical simulation offers a means by which surgical variability will decrease, thus improving clinical outcomes. 


\section{DisClOSURES}

Won Hyung Ryu received an Alberta Innovates Health Solutions Clinician Fellowship grant. Sonny Chan and Garnette Sutherland do not have anything to disclose.

\section{REFERENCES}

1. Sadaba JR, Urso S. Does the introduction of duty-hour restriction in the United States negatively affect the operative volume of surgical trainees? Interact Cardiovasc Thorac Surg. 2011; 13(3):316-9.

2. Bell RH Jr, Biester TW, Tabuenca A, Rhodes RS, Cofer JB, Britt LD, et al. Operative experience of residents in US general surgery programs: a gap between expectation and experience. Ann Surg. 2009 May;249(5):719-24.

3. Fonseca AL, Reddy V, Longo WE, Gusberg RJ. Graduating general surgery resident operative confidence: perspective from a national survey. J Surg Res. 2014;190(2):419-28.

4. Teman NR, Gauger PG, Mullan PB, Tarpley JL, Minter RM. Entrustment of general surgery residents in the operating room: factors contributing to provision of resident autonomy. J Am Coll Surg. 2014 Oct;219(4):778-87.

5. Dagi TF. Commentary: the roles and future of simulation in neurosurgery. Neurosurgery. 2013;73(Suppl 1):4-5.

6. Walter AJ. Surgical education for the twenty-first century: beyond the apprentice model. Obstet Gynecol Clin North Am. 2006; 33(2):233-6; vii.

7. Haji FA, Clarke DB, Matte MC, Brandman DM, Brien S, de Ribaupierre S, et al. Teaching for the Transition: the Canadian PGY-1 Neurosurgery 'Rookie Camp'. Can J Neurol Sci. 2015; 42(1):25-33.

8. Shakur SF, Luciano CJ, Kania P, et al. Usefulness of a Virtual Reality Percutaneous Trigeminal Rhizotomy Simulator in Neurosurgical Training. Neurosurgery. 2015;11(Suppl 3):420-5.

9. Ray WZ, Ganju A, Harrop JS, Hoh DJ. Developing an anterior cervical diskectomy aand fusion simulator for neurosurgical resident training. Neurosurgery. 2013;73(Suppl 1):100-6.

10. Gasco J, Holbrook TJ, Patel A, Smith A, Paulson D, Muns A, et al. Neurosurgery simulation in residency training: feasibility, cost, and educational benefit. Neurosurgery. 2013;73(Suppl 1):39-45.

11. Royal College of Physicians and Surgeons of Canada. Neurosurgery: Program Directors. http://www.royalcollege.ca/portal/page/portal/ rc/credentials/accreditation/arps/specialty/neurosurgery.
12. Canadian Post-M.D. Education Registry. 2014-2015 Annual census of post-M.D. trainees. 2015.

13. Ganju A, Aoun SG, Daou MR, et al. The role of simulation in neurosurgical education: a survey of 99 United States neurosurgery program directors. World Neurosurg. 2013;80(5):1-8.

14. Kshettry VR, Mullin JP, Schlenk R, Recinos PF, Benzel EC. The role of laboratory ddissection training in neurosurgical residency: results of a national survey. World Neurosurg. 2014;82(5):554-9.

15. Gelinas-Phaneuf N, Del Maestro RF. Surgical expertise in neurosurgery: integrating theory into practice. Neurosurgery. 2013;73 (Suppl 1):30-8.

16. Kirkman MA, Muirhead W, Nandi D, Sevdalis N. Development and psychometric evaluation of the "Neurosurgical Evaluation of Attitudes towards simulation Training" (NEAT) tool for use in neurosurgical education and training. World Neurosurg. 2014; 82(3-4):284-91.

17. CARTER BN. The fruition of Halsted's concept of surgical training. Surgery. 1952;32(3):518-27.

18. Reznick RK, MacRae H. Teaching surgical skills-changes in the wind. N Engl J Med. 2006;355(25):2664-9.

19. Harris JD, Staheli G, LeClere L, Andersone D, McCormick F. What effects have resident work-hour changes had on education, quality of life, and safety? A systematic review. Clin Orthop Relat Res. 2015;473(5):1600-8.

20. Jagannathan J, Vates GE, Pouratian N, Sheehan JP, Patrie J, Grady MS, et al. Impact of the Accreditation Council for Graduate Medical Education work-hour regulations on neurosurgical resident education and productivity. J Neurosurg. 2009;110(5):820-7.

21. Cohen-Gadol AA, Piepgras DG, Krishnamurthy S, Fessler RD. Resident duty hours rreform: results of a national survey of the program directors and residents in nneurosurgery training programs. Neurosurgery. 2005;56(2):398-403.

22. Stredney D, Rezai AR, Prevedello DM, Elder JB, Kerwin T, Hittle B, et al. Translating the simulation of procedural drilling techniques for interactive neurosurgical training. Neurosurgery. 2013; 73(Suppl 1):74-80.

23. Schirmer CM, Mocco J, Elder JB. Evolving virtual reality simulation in neurosurgery. Neurosurgery. 2013;73(Suppl 1):127-37.

24. Connorr D. Simulation training in Neurosurgery: History and future direction. http://www.aans.org/pdf/YoungNeurosurgeons/YNC\% 20Newsletter\%20Fall\%202014.pdf.

25. Rezai A. President's Message - The thriving and innovative CNS. https://www.cns.org/news-advocacy/messages-president/ presidents-message-thriving-and-innovative-cns. 